\title{
A boneca de Kokoschka e o direito a narrar-se de novo: o papel dos enredos de fé, amor e arte na reconstrução da identidade pós-trauma
}

\author{
Francilene Maria Ribeiro Alves Cechinel ${ }^{*}$
}

Em seu livro intitulado A espécie fabuladora: um breve estudo sobre a humanidade (2010), Nancy Huston afirma que a narrativa se desenvolveu em nossa espécie como uma técnica de sobrevivência. É através das narrativas que transformamos nossa existência terrestre em uma trajetória dotada de um sentido (com significação e direção) e é graças a elas que suportamos mais facilmente o vazio de sentidos ao nosso redor. São essas narrativas que nos fabricam, penetrando em nosso cérebro desde nossos primeiros anos de vida, compondo "camadas e camadas de impressões compiladas em histórias" (Huston, 2010, p. 23) nas quais passamos a acreditar e, finalmente, confeccionando nossa identidade, arranjando-nos um ego. As ficções utilizadas na formação de nosso ego constroem nossas verdades, unindo-nos aos nossos semelhantes em enredos compartilhados e reforçando a si próprias através da presença dos outros em nós. Segundo Huston, é por isso que "na deportação, na escravidão, no genocídio, as vítimas devem ser despojadas previamente das suas histórias", porque não existe "nada mais desestabilizador, mais ameaçador, mais perturbador para um indivíduo do que ver bruscamente dispersadas, como num jogo de boliche, as suas bases identitárias" (Huston, 2010, p. 92).

O poder dessas ficções que nos criam e recriam é também o tema central de A boneca de Kokoschka (2010), obra do escritor português Afonso Cruz lançada em 2010 e contemplada com o Prêmio União Europeia para a Literatura em 2012. Utilizando como ponto de partida os momentos finais da Segunda Guerra Mundial na cidade alemã de Dresden, Cruz põe em evidência a luta de cada ser humano para manter unidos os pedaços de sua identidade e proteger seus contornos diante da violência brutal da guerra, da força inexorável do tempo e da inevitável entropia do universo. Com tal objetivo, diversas metáforas ressaltam, ao longo do enredo, os constantes embates entre morte e vida, dispersão e aglutinação, caos e organização em nossa existência. Enquanto isso, seus personagens buscam um novo espaço para sobreviver não apenas às bombas que aniquilam os corpos, mas também às trágicas lembranças e sentimentos que os desafiam a criar um futuro a partir de um passado em ruínas. Em meio aos seus destroços, é através da res-

Doutora em História da Literatura pela Universidade do Rio Grande, Brasil. E-mail: francilene.cechinel@gmail.com. 
tauração das narrativas de fé, amor e arte em suas vidas que os protagonistas da obra se reconectam a si mesmos e à humanidade, encontrando novos significados e direções, apesar do vazio de sentidos que continua a assombrá-los.

\section{Sobre caves, marionetes e puzzles}

Breve e luminosa, a escrita de Afonso Cruz parece a princípio ser incapaz de abranger os aspectos mais dramáticos da história que se propõe a apresentar. A leveza da palavra conduz o leitor em um voo delicado, mas ameaçado a todo instante pela atrocidade dos fatos relatados. Por baixo do texto, entretanto, o autor constrói suas "caves", mostrando que "a construção de edifícios não se limita a tijolos empilhados e pedras e telhados, também são espaços vazios, o nada a crescer dentro das coisas como estômagos" (CRUZ, 2012, p. 15). Assim, o vasto conjunto de estômagos espalhados ao longo da obra vai sendo alimentado e costurado para formar a trama firme e subterrânea que confere densidade e profundidade ao que é narrado na superfície. Exemplo marcante de tais metáforas são os bonecos, que se confundem com o mito do Golem (CRUZ, 2012, p. 37-40), ${ }^{1}$ quando interpretados à partir da relação entre Isaac Dresner e Bonifaz Vogel, e com o mito de Pigmalião (CRUZ, 2012, p. 161), ${ }^{2}$ quando associados às experiências amorosas de Oskar Kokoschka e de Eduwa. Estes dois mitos, por sua vez, remetem ao mito da criação de Adão, segundo o qual todos descendemos de um boneco de barro que só se torna humano ao ser tocado pelo sopro divino e através do qual nos igualamos às metáforas de A boneca de Kokoschka: "todos nós somos marionetas, uns mais bonecos do que outros, uns mais idolatrados do que outros" (CruZ, 2012, p. 160).

Seguindo tal ideia, os personagens centrais do livro encontram-se, em vários momentos, esvaziados de sentido, como corpos inanimados em busca de narrativas que os cerquem de novos olhares sobre si mesmos e que lhes devolvam, assim, o caráter humano. A história verídica do pintor Oskar Kokoschka funciona como fio que amarra todas estas ideias ao redor da mesma teoria: "Uma pessoa não existe apenas por ter um corpo. Precisa ter uma vida social. Precisa da palavra, da alma. Precisamos de testemunhos, dos outros" (CRUZ, 2012, p. 160). É com histórias, rumores, ficções, que Kokoschka tenta inutilmente preencher de vida (ou de Alma, Mahler) a boneca que mandou fazer. Da mesma forma, Adele Varga tentava dar vida às bonecas que o pai lhe dava: "vestia-as e levava-as a passear, levava-as à ópera, dava-lhes banho e dormia com elas, provando assim que a ficção, e não o cão, é a melhor amizade do homem" (CRUZ, 2012, p. 207). Mas também são as histórias de fé de Eduwa que transformam a boneca abandonada por Kokoschka em

\footnotetext{
Parte da tradição mística judaica, o Golem é um ser artificial feito de lama, que ganha vida ao ser marcado com palavras mágicas por alguém com poderes divinos e a quem ele passa a servir.

2 Na mitologia grega, o rei Pigmalião, sem conseguir encontrar uma esposa que correspondesse aos seus padrões de beleza e recato, esculpe uma mulher de pedra que atende perfeitamente seus ideais e por quem se apaixona. Com pena do rei, a deusa Afrodite resolve dar vida à estátua.
} 
uma Oxum viva e capaz de gerar vida ${ }^{3}$ e são as palavras de Isaac, dentro e fora do cérebro de Bonifaz, ${ }^{4}$ que criam para ambos uma nova vida, unindo-os em uma mesma família. ${ }^{5}$

Como uma das fontes primordiais de enredos que ligam as pessoas entre si, a fé tece histórias que nos levam a sentir que estamos incluídos em algo maior e, por consequência, nos ajudam a emergir e a sobreviver como indivíduos. Segundo Huston (2010, p. 65), "para que o eu possa surgir, é preciso fazê-lo existir em meio a vários nós" e "a fé reforça cada indivíduo em si mesmo, e une eficazmente os indivíduos entre si" (Huston, 2010, p. 79). Porém, como todas as demais ficções que nos compõem, as histórias de fé também geram exclusões - dos "mais ou menos próximos ou ameaçadores eles" (Huston, 2010, p. 65) - e alimentam orgulhos que, levados ao extremo, semeiam o esvaziamento e a morte. Tal contraste é ressaltado em A boneca de Kokoschka pelos personagens Isaac e Tsilia, ambos duplamente estigmatizados e, por isso, condenados a serem sempre eles (e nunca parte de algum nós), esvaziados de sua essência coletiva e desafiados a construírem-se como indivíduos em meio a tantos processos de destruição (interna e externa). Isaac, por ser judeu e alemão, tem sua família dizimada pelos nazistas e, depois, sua cidade aniquilada pelos ataques dos Aliados contra os nazistas. Tsília, uma judia que carrega no corpo as chagas de Cristo, é obrigada a abandonar sua família por não se encaixar nos padrões judaicos e, então, é perseguida pelos nazistas por encaixarse nos mesmos padrões.

Pisados por "inúmeras perspectivas, avassaladoras" (CRUZ, 2012, p. 237), Isaac e Tsilia se encontram, cheios apenas de luz apagada e frio insuportável, e, no abrigo que oferecem um ao outro, reconstituem-se em torno de uma nova fonte de ficções: o amor. Em A boneca de Kokoschka, o amor é a força aglutinadora que "vai juntando as peças que pode - como um velho reformado a jogar dominó", enquanto o universo, "feito de ódio, de corrupção, de coisas a afastarem-se umas das outras", se expande e embaralha tudo (CRUZ, 2012, p. 173). Na contramão da natural e irremediável entropia cósmica, as narrativas de amor dão suporte à vida em sua tarefa de unir células, organismos e seres e de mantê-los assim unidos, a lutar com todas as forças contra sua destruição. Amar alguém, então, é valorizar as narrativas que compõem o ser amado e recriá-las dentro de si, ad infinitum, para que continuem se desenvolvendo, protegidas do universo e entrelaçadas às nossas. Como resultado deste processo, vamos ganhando e gerando "uma eternidade

3 Em: "a criança era filha da sua devoção, das suas palavras, do seu amor, no fundo. E quem somos nós para negar que os filhos nascem disso mesmo?" (CRUZ, 2012, p. 164).

4 Referência a mais um boneco, Pinóquio (da obra de Carlo Collodi), e sua relação com seu grilo falante (sua consciência, o que o ensina a se tornar humano): "Isaac Dresner dizia que era um grilo para ele. E que ele, Bonifaz Vogel, era um boneco de madeira” (Cruz, 2012, p. 37).

5 Em: "Um filho cujas recordações jamais o permitiriam pegar no colo. Mas era como um filho. No entanto, oficialmente, era ao contrário" (CRUZ, 2012, p. 47) e "Não era o meu pai biológico, mas as relações não se constroem apenas com biologias” (CRUZ, 2012, p. 218). 
de novos esboços, cada vez melhores, para nos encontrarmos um dentro do outro como aquelas bonecas ${ }^{6}$ russas" (CRUZ, 2012, p. 93).

Ao longo do livro, dois casos refletem os efeitos das ficções de amor que nos compõem: a troca de cartas entre Bonifaz Vogel (através de Isaac) e a Condessa Malgorzata Zajac e a busca de Anasztázia Varga (através de Adele) por Mathias Popa. Entre Vogel e a Condessa, tais ficções funcionam como um último sopro de vida a invadir os corpos um do outro em busca de um envoltório menos perecível onde possam sobreviver ao tempo e à morte. Sob o olhar amoroso, eles voltam a existir com nitidez ${ }^{7}$ tão impressionante que, pela primeira vez no livro, a voz de Vogel invade a mente de Isaac e, invertendo os papéis estabelecidos desde seu primeiro encontro, transforma-o em sua marionete. ${ }^{8}$ Já no segundo caso, nem o tempo e nem a morte conseguem destruir as ficções de amor que Anasztázia alimenta e que, mesmo afrontadas por outras versões de Popa, faz sobreviver para além de ambos, no corpo e na vida de sua neta. Adele, então, é o produto do entrelaçamento das ficções de seus avós, um personagem (uma boneca) a quem Anasztázia e Popa deram um nome, seu sangue e uma história de amor (conduzindo Adele até Miro Korda) que continuam a escrever, independente de onde estejam (Popa já morto e Anasztázia à beira da morte).

Analisada para além da questão amorosa, a trajetória de Mathias Popa nos leva ainda mais fundo na teoria central de A boneca de Kokoschka: se é o olhar dos outros que nos dá a vida e se são várias as testemunhas de nossa existência, nós somos o conjunto de diferentes ângulos sobrepostos. Seguindo tal perspectiva, a narrativa de Cruz constrói o personagem Popa a partir de dois momentos diametralmente opostos: sua juventude, a partir do encontro com Tsilia em sua adolescência; e sua velhice, a partir da convivência com Isaac em seus últimos meses de vida. Unindo estas pontas, o livro apresenta a versão do próprio personagem sobre sua história (no livro que publica pela editora de Isaac) e, negando a precedência de qualquer uma destas versões sobre as demais, acompanha a busca de Adele pelo "Popa aperfeiçoado, mítico, provavelmente mais alto", que vive apenas nas memórias de sua avó. A esta lista de esboços, finalmente, Isaac acrescenta mais um, ${ }^{9}$ garantindo sua perpetuação através de Adele e das sobreposições que caberá a ela fazer, como ele sugere:

6 A referência às bonecas russas (aqui) e às marionetes (no parágrafo seguinte) remete mais uma vez à metáfora já discutida na segunda página deste artigo.

7 Em: "Sinto-me mais viva, quando sei que repara em mim, e calculo que o Sr. Vogel sentirá a mesma coisa ao ler estas palavras. São os outros que nos fazem viver, especialmente os que nos amam. Eu, de uns anos para cá, estava a perder a nitidez. Foram as suas palavras que me devolveram alguns contornos" (CRUZ, 2012, p. 220).

8 Em: "apesar de o senhor parecer o mestre de uma marioneta, a verdade é outra. Foi Bonifaz Vogel que o fez falar [...] Temo que, nesta história de amor, o senhor seja a marioneta mais evidente" (CRUZ, 2012, p. 221).

9 Em: "O Mathias Popa que eu descrevi à Adele existe num tempo vertical, um bocadinho ao lado, talvez à esquerda, apesar de não existir na nossa seta passado/futuro” (Cruz, 2012, p. 237). 
Tenho a certeza de que o Mathias Popa que faz parte das memórias de sua avó é muito diferente do Mathias Popa que eu conheci. Teríamos que juntar os dois para percebê-lo melhor. Juntar camadas sobre camadas como faz a minha mulher ao pintar. O Mathias Popa da sua avó é uma invenção da sua avó [...] Esse Popa não morre, ou melhor, morre com a sua avó. Um ângulo, que é disso que o mundo é feito: de ângulos sobrepostos (CRUZ, 2012, p. 231).

Na elaboração de sua rede de metáforas, Afonso Cruz utiliza também diversos exemplos dessa sobreposição de camadas que compõe a vida humana e ressalta a importância das narrativas da arte no imprescindível processo de percepção e compreensão desta multiplicidade. Neste sentido, o ponto mais marcante do livro A boneca de Kokoschka é, com certeza, o fato de, assim como as bonecas russas, conter dentro de si outro livro, também intitulado "A boneca de Kokoschka". Escrito por outro autor (Mathias Popa), o livro dentro do livro redimensiona a obra de Cruz, ampliando os ângulos de seus personagens, dotando-os de novas verdades e lembrando-nos que a literatura pode fazer o mesmo conosco, despertando em nós perspectivas que ainda não vivenciamos ou percebemos. Ao recriar Isaac, "muito mais grandioso do que é", como Samuel Tóth, ${ }^{10}$ Popa o faz lembrar da "juventude passada a contar as letras da Torá, a ler o Zohar, o Sefer HaOr e a criar golems embaixo da cama" (CRUZ, 2012, p. 97), ou seja, a experimentar o poder divino das palavras para criar vida a partir de peças mortas. Exatamente como ele volta a fazer no momento em que recria Mathias Popa, então já morto, na mente de Adele. Ao identificar-se com o personagem Samuel, Isaac reencontra dentro de si outro Isaac (que havia ficado preso em seu passado traumático), abre o alçapão que o leva para fora de sua cave e, retribuindo na mesma moeda, abre com sua ficção um alçapão por onde a memória de Popa também ganha nova vida.

Além da literatura, a pintura e a música também têm papel fundamental em A boneca de Kokoschka, funcionando como três grandes eixos que unem personagens e temas e como fonte primordial de ficções e metáforas que compõem, de modo especial, Mathias Popa (literatura), Tsilia Kacev (pintura) e Miro Korda (música). ${ }^{11}$ Em diferentes momentos da narrativa, é a arte (nestas três formas) que ajuda o ser humano a perceber suas múltiplas camadas, a entrar em sintonia com sua capacidade de criação e, principalmente, a evitar um grande perigo: esquecer que "o que não é real é retratar as coisas somente por um ângulo", que "a verdade tem muitas perspectivas" e que, "se nos limitarmos a uma, estamos muito próximos do erro absoluto" (CRUz, 2012, p. 44). A arte abre alçapões por onde escapamos da cristalização que nos aprisiona em uma cave, um aquário, um útero, ao par irredutível nós/eles, e, consequentemente, ao que Huston (2010) define como "a es-

10 Referência ao deus egípcio Thoth, personificação da escrita e da palavra divina.

1 Afonso Cruz é também músico e ilustrador e o grande número de metáforas, exemplos, personagens, fatos históricos e descrições extremamente detalhadas relacionados à literatura, à pintura e à música é uma característica que marca toda sua produção literária. 
trutura de base de todas as narrativas primitivas", ${ }_{12}$ o "Arque-texto da espécie humana": "Você é dos nossos. Os outros são os inimigos" (Huston, 2010, p. 65). Na luta contra tais reducionismos e seus efeitos, Tsilia é, com certeza, o personagem que nos faz ver mais claramente como os caminhos da arte nos oferecem uma alternativa para as feridas causadas pela exclusão:

Os meus ângulos são todos os ângulos. Um quadro dos meus tem todas as perspectivas. Também inclui as fantasias. E até o inimaginável. É do inimaginável que se faz a arte. São as perspectivas mais densas, as primeiras, as que servem de base às outras, às visíveis. Eu podia explicar-te o mundo, mas é tão difícil. É por isso que eu pinto, é a única maneira que tenho de mostrar todas as fatias da realidade e todas as fatias da ficção (que é muito mais extensa do que a realidade, infinitamente mais extensa). Tudo a óleo ou a acrílico. Eu sou uma judia com chagas, eu sou uma série de ângulos sobrepostos, de realidades umas em cima das outras, religiões misturadas, tão misturadas que me fazem sangrar (CRUZ, 2012, p. 237).

Além disso, são também as representações da arte em $A$ boneca de Kokoschka que conduzem o leitor até o outro lado desta mesma questão, ou seja, até a possibilidade de compreensão de nossas verdades e identidades múltiplas e em construção e, logo, até a capacidade de reconhecimento da multiplicidade dos outros e de identificação com seres que não se parecem conosco. ${ }^{13}$. Ao longo do enredo, diferentes momentos sugerem que é a abertura para tal forma de compreensão que nos desvia do fluxo universal dispersivo e caótico (a entropia) e que nos oferece novas chances de incluir (a nós mesmos e aos outros), de reorganizar (em vez de descartar) e de unir peças que antes pareciam sem sentido. É neste contexto que a metáfora do puzzle, também recorrente no livro, se destaca associada à representação de um sentido mais amplo e ininteligível, que nos conecta e move mesmo nos cenários mais incoerentes, assim como a fé, o amor e a arte. Diante de toda a destruição, a dor e a morte que o evento inicial da obra nos apresenta, apenas Deus seria capaz de enxergar os seres humanos sob todos os ângulos que precisam ser reconstituídos, ${ }^{14}$ apenas o amor seria capaz de aglutinar tantas discrepâncias em uma nova vida, ${ }^{15}$ apenas a arte poderia dar forma ao inimaginável.

Entretanto, ao nos lembrar que "Deus nem é um grande jogador" (CruZ, 2012, p. 25) e que o amor é "um mero produto bioquímico fabricado por glândulas e outras

12 "Ser primitivo é colar-se à sua identidade como se esta fosse uma realidade inamovível e se identificar exclusivamente com aqueles que se parecem com você" (Huston, 2010, p. 127).

13 Segundo Huston (2010, p. 72): "Ser civilizado é reconhecer a identidade como uma construção, é se interessar por mil textos e, através deles, aprender a se identificar com seres que não se parecem com a gente"

14 Assim, "A visão de uma pessoa de todas as perspectivas possíveis assemelha-se ao modo como o Eterno nos vê" (Cruz, 2012, p. 69). "Os vivos foram ficando cada vez mais mortos, eram largos milhares de civis, estendidos pelo chão, pelo ar, com os corpos dilacerados e divididos em pedaços, em peças inúteis. Um puzzle para Deus" (CRUZ, 2012, p. 39).

15 Assim, "Precisamos de nos lembrar que a vida é um fenômeno que resulta do amor, da união, entre todas as peças que a compõem" (CRUZ, 2012, p. 173). 
coisas viscerais" (CRUz, 2012, p. 173), Cruz nos alerta mais uma vez para a fragilidade das ficções que compõem nossas verdades e, como finalmente Samuel Toth resume através de sua arte, para a força das verdades que compõem nossas ficções:

Nós aqui, fabricamos vidas. Não fazemos ficções, fazemos a realidade. Multiplicamos o homem, criamos novas maneiras de ver as coisas. [...] A criação de vidas prolonga-nos até o infinito. É tornando-nos muitos que chegamos a ser todos, que é o Todo e que é o Um. O homem tem de ser visto de vários ângulos ao mesmo tempo, sobrepostos. O mesmo homem deve ser cheio de incoerências e anacronismos e deve saber viver com isso. Colocarmo-nos no lugar dos outros, enchermo-nos de outros, dos inimigos, dos amigos, dos ladrões, das putas, dos ministros, dos taxistas, dos engenheiros, dos embusteiros, dos generosos, dos selvagens, dos mentirosos, dos avessos, dos miseráveis, dos budistas, dos banqueiros, dos anarquistas, dos pilotos de aviões, dos porcos, dos santos, dos cristãos, dos vizinhos, dos loucos, dos abomináveis, de todos, todos sem excepção, até dos familiares longínquos e próximos. Todos dentro de nós para que nos seja fácil compreender aquelas diferenças e, eventualmente, encontrar uma paz no meio dessa tensão. As guerras têm mais dificuldades de existir quando as pessoas se compreendem umas às outras. As bombas caem menos, os prédios tendem a ficar de pé, os corpos não se despedaçam com a mesma frequência, os braços deixam de voar e é possível que as gaiolas deixem de existir, os campos de concentração passem a ser museus para a nossa memória (CRUZ, 2012, p. 171-172).

\section{Sobre traumas e reconstruções}

Analisando por outro viés, podemos ainda abordar A boneca de Kokoschka como uma obra centrada em um episódio traumático: a destruição de uma cidade alemã aberta, sem defesa aérea e sem objetivos militares, depois de ser atingida por 3.900 toneladas de bombas despejadas durante três dias. Por seus números, ${ }^{16} \mathrm{o}$ ataque a Dresden é lembrado como um dos piores exemplos de sacrifício civil provocado por bombardeio estratégico e, por ter atingido com tamanha crueldade um local que servia de abrigo a feridos e refugiados quando a guerra já chegava ao fim, é considerado por muitos um crime de guerra ainda não reconhecido. Entre tantos episódios monstruosos como os que compõem todas as guerras, tal tragédia chama atenção pela sordidez de seu planejamento, pelo ataque repetido às mesmas vítimas e por romper novamente os limites da violência, da dor e da devastação que já pareciam ter sido levados ao extremo. Ao contar esta história a partir de seu impacto nas vidas de Bonifaz (um alemão católico), Isaac (um alemão judeu) e Tsilia (uma judia bielorussa), Afonso Cruz a transforma em mais uma metáfora na rede de delicadezas e profundidades que seu texto constrói. Dresden aquele "puzzle feito de infinitos estilhaços", "não só de cimento e ossos, mas de almas, uma confusão de matéria e de espírito, uma sopa muito pouco cartesiana"

\footnotetext{
16 Trinta e nove quilômetros quadrados de Dresden queimaram atingindo mais de 1000 graus Cel-
} sius e matando mais de 300.000 pessoas. 
(CRUZ, 2012, p. 41) - se torna um retrato da "humanidade feita em pedaços, onde apenas sobra o assombro de uma boca aberta" (Cruz, 2012, p. 38).

Destituídos de tanto daquilo que os constituía física, moral e emocionalmente, os personagens de Cruz se resumem a alguns poucos traços do que já foram e a muitos vazios, que agora compartilham intimamente com outros seres antes tão distantes de sua realidade. A incapacidade de racionalizar e comunicar estes vazios se torna parte da natureza dos sobreviventes que, como os pássaros da loja de Bonifaz, passam a cantar em silêncio, reconstruindo sua identidade e sua expressão em torno dos destroços e das ausências que agora também os compõem. Tal transformação segue o processo descrito por autores como Primo Levi, Robert Antelme e, principalmente, Theodor Adorno, como explica Jeanne Marie Gagnebin em seu livro Lembrar escrever esquecer (2009):

A mais nobre característica do homem, sua razão e sua linguagem, o logos, não pode, após Auschwitz, permanecer o mesmo, intacto em sua esplêndida autonomia. A aniquilação de corpos humanos nessa sua dimensão originária de corporeidade indefesa e indeterminada como que contamina a dimensão espiritual e intelectual, essa outra face do ser humano. [...] Criar em arte - como também em pensamento - "após Auschwitz" significa não só rememorar os mortos e lutar contra o esquecimento, tarefa por certo imprescindível, mas comum a toda tradição artística desde a poesia épica. Significa também acolher, no próprio movimento da rememoração, essa presença do sofrimento sem palavras nem conceitos que desarticula a vontade de coerência e de sentido de nossos empreendimentos artísticos e reflexivos (GAGNEBIN, 2009, p. 77-78).

Em A boneca de Kokoschka, o desafio de recriar a si mesmo após o Holocausto e a aniquilação das cidades alemãs é relatado diversas vezes e por diferentes ângulos. ${ }^{17}$ No caso de Bonifaz, sua natureza já tão cheia de "reticências" torna mais difícil uma reconstrução e, então, seus vazios e silêncios se avolumam tornando-o "cada vez mais invisível” (Cruz, 2012, p. 68). Tsilia encontra em uma nova linguagem (a pintura) a possibilidade de expressar todas as fatias de ficção e realidade que foi forçada a ver e impossibilitada de esquecer, porém, suas chagas seguem sangrando. E Isaac - atacado com a mesma intensidade tanto por ser judeu quanto por ser alemão - busca em suas memórias as raízes das ficções que o constituíram e sobre as quais volta a se erguer (ainda que mancando sob o peso de seus mortos), mas

${ }_{17}$ Em um contexto mais restrito, as tragédias pessoais dos músicos Django Reinhart e Pat Martino são lembradas pelo personagem Miro Korda como exemplos da reconstrução de um indivíduo através de sua arte. Considerado um dos melhores guitarristas de todos os tempos, Django Reinhardt teve que reaprender a tocar após ter sua mão esquerda queimada durante um incêndio. Ao se reinventar como guitarrista, Django criou o Gipsy jazz. Conhecido por sua abordagem matemática ao instrumento, Pat Martino é outro guitarrista de jazz mundialmente famoso. Tocando profissionalmente desde adolescente, Pat foi acometido por um aneurisma cerebral aos 32 anos e, após a operação, perdeu quase completamente sua memória. Para reaprender a tocar, Martino passou a estudar seus próprios discos. 
só através da literatura se encontra finalmente com o que deveria ter se tornado. A transformação dos três em uma família, criada sobre as ruínas da humanidade e a partir dos gestos simples de Isaac, mostra ser possível que algo novo nasça do pouco que restou. Porém, as lágrimas que lhes vêm aos olhos cada vez que novamente se dão as mãos nos lembram que o trauma continuará impregnado em seus sentidos até o final de sua existência.

A invisibilidade de Vogel, as chagas de Tsilia e o reumatismo de Isaac são sinais do trauma que carregam, da "ferida aberta na alma, ou no corpo, por acontecimentos violentos, recalcados ou não, mas que não conseguem ser elaborados simbolicamente, em particular sob a forma de palavra, pelo sujeito" (Assmann, 2006 apud GAGNEBIN, 2009, p. 110). Esta visão das marcas que nossas vivências imprimem sobre nossos sentidos e das consequências físicas do trabalho de rememoração e luto se conecta a uma concepção de memória que Cruz apresenta em diferentes momentos de sua obra. Em A boneca de Kokoschka, o que permanece gravado nos seres humanos tem precedência sobre as demais formas de registro do vivido: as memórias se guardam "na cabeça, no corpo todo, na pele, mas também em caixas de cartão escondidas/arrumadas em guarda-fatos" (CRUZ, 2012, p. 120, grifo nosso). Desta forma, mesmo o que não conseguimos esconder nem organizar (ainda que incomunicável através de nossa elaboração racional, como no caso de um trauma) permanece dizendo mais sobre os indivíduos e sobre os eventos do que cartões, fotografias, desenhos ou todo um livro escrito a respeito (como no caso do amor de Anasztázia por Popa). Em suas memórias, Isaac conta como seu pai tentava inutilmente desenhar o rosto do avô, mas conclui o capítulo com o seguinte trecho: "Uma vez perguntei-lhe porque é que ele repetia tantas vezes as frases do meu avô e ele respondeu assim: - Repetir o que teu avô dizia é como olhar para uma fotografia dele. Afinal, o meu pai não precisava de saber desenhar" (CRUZ, 2012, p. 57).

Como descrito por Márcio Seligmann-Silva, os sobreviventes de Dresden apresentados por Cruz sofrem com a "cisão entre a linguagem e o evento" (Seligmann-Silva, 2003, p. 46) e "entre um eu que observa e outro que é abandonado, a saber, o corpo" (SeligmanN-Silva, 2005, p. 68). Assolados simultaneamente pela necessidade de acessar a experiência inimaginável que viveram e pela impossibilidade de recordar e recobrir verbalmente este "real", ${ }^{18}$ eles se encontram em meio a "um quebra-cabeças imenso, com nível de dificuldade fascistas" (CRUZ, 2012, p. 39), no qual as peças feitas de memória e sentimentos não cabem mais. ${ }^{19}$ Então, a única saída encontrada por eles é a arte. Equipados com sua própria imaginação, Tsilia desafia - ainda que sem nunca totalmente submeter

${ }_{18}$ Assim, "o dado inimaginável da experiência concentracionária desconstrói o maquinário da linguagem” (Seligmann-Silva, 2003, p. 46).

19 Assim, "Há memórias que não cabem no corpo. O sorriso de um filho é uma peça de um puzzle que é maior do que o puzzle a que pertence" (CRUZ, 2012, p. 41). 
(Seligmann-Silva, 2003, p. 46) - a intraduzibilidade ${ }^{20}$ de seu testemunho através da pintura e Isaac acessa "o 'tu' ilhado que existe dentro dele" (SELIGmanNSiLva, 2005, p. 70) ${ }^{21}$ através da literatura. Suas feridas continuam abertas, "não podem ser curadas nem por encantações nem por narrativas" (AssMANN 2006 apud GAGNEBIN, 2009, p. 110), mas, a partir da expressão artística, eles se aproximam do trabalho do Eterno e atingem o impossível: "juntar coisas mortas e fazer uma coisa viva" (Cruz, 2012, p. 40).

Presos na circunferência "onde todo o drama humano se encerra" (CRUZ, 2012, p. 54), Isaac e Tsilia ainda oscilam entre morte e vida, dispersão e aglutinação, caos e organização, porém, dialogando através da arte com o mais escuro em si, ${ }^{22}$ ambos saltam rumo a versões mais luminosas de suas próprias ficções. ${ }^{23}$ Menos disposto a enfrentar seus abismos, Mathias Popa se apresenta como uma espécie de antagonista que, aprisionado em suas assoalhadas por sua própria covardia, se esquiva dos confrontos com a dor, mas, pelo mesmo motivo, é condenado a uma existência estéril, ${ }^{24}$ solitária e fracassada. Ao contrário de Isaac e Tsilia, que constroem laços capazes de unir o improvável (como os da família que passam a compor), Popa passa a romper todos os fios que o ligam a sua história (com sua família de origem e com a família que surge a partir dele e de Anasztázia) e a destruir tudo aquilo que possa construir uma via de diálogo com seus sentimentos, inclusive, sua arte:

Um dia, a ler o jornal, perdi todo o sentido poético. Senti-me vazio, sabe, completamente oco. Uma pessoa lê o jornal e perde a poesia. Não foi por causa da rejeição das editoras e essas coisas, foi esta sociedade. As guerras e isso (na altura tinha começado a Guerra das Areias, entre Marrocos e a Argélia e eu já não podia com mais guerras). Peguei na minha obra toda, mais de quatro mil páginas $\mathrm{A} 4$, e enterrei tudo num terreno baldio perto de casa (CRUZ, 2012, p. 83).

${ }^{20}$ Assim, "o Holocausto foi não apenas sinistro e horrendo, mas também absolutamente nada fácil de compreender em termos habituais, 'comuns'. Foi escrito em seu próprio código, que tinha de ser decifrado primeiro para tornar possível a compreensão" (BAUMAN, 1998, p. 10).

${ }^{21}$ No livro O local da diferença: ensaios sobre memória, arte, literatura e tradução (2005), SeligmannSilva aborda os sintomas da síndrome do sobrevivente, citando entre eles "uma cisão interna entre um eu que observa e outro que é abandonado, a saber, o corpo" (p. 68) e a necessidade imperativa de estabelecer uma ponte entre estes eus através da narrativa do testemunho.

${ }^{22}$ Assim, "No fundo, é tudo a mesma coisa: uma caverna, uma cave, um poço, o submundo, o inferno, o Egipto, as Finanças, isso é tudo o mesmo arquétipo" (Cruz, 2012, p. 97).

23 Assim, "É da escuridade da cova que uma pessoa começa a crescer pela vertical acima. Primeiro constrói-se um buraco todo vazio, só feito de abismo. Quando mergulhamos nesse lugar escuro, acontece que, por irmos para baixo, levantamos voo. Mergulhar nesse abismo é como flectir as pernas para saltar. Para baixo, antes de bater com a cabeça no céu" (CRUZ, 2012, p. 57).

24 Assim, "Eu nunca tive muita coragem de me enfiar no escuro. O sofrimento tem-me passado um pouco ao lado. É certo que não gosto de guerras, nem de mulheres sem ancas espaçosas, mas, de resto pouca coisa me afeta. Prefiro o vinho e as pizzas ao sofrimento. Deve ser por isso que não passo deste destroço" (CRUZ, 2012, p. 97). 
Entretanto, nos momentos finais de sua história, diante de um novo confronto com a morte (agora, inevitável), Popa retorna a sua escrita como único caminho para perseguir ${ }^{25}$ e traduzir seu eu abandonado. É nos pedaços mais sensíveis de si mesmo, enterrados há tanto tempo para sua própria proteção, que Popa deposita novamente suas esperanças de criar vida e, agora também, de cumprir o dever de lembrar. Lembrar para poder morrer e para continuar vivo na memória de outros, lembrar para "que a nossa passagem pela Terra não seja meramente uma existência, mas uma vida, ou seja, que ela nos pareça seguir uma trajetória, corresponder a um destino, ter um Sentido" (Huston, 2010, p. 59), lembrar para revolver e adubar o solo de onde ainda é possível extrair poesia, mesmo quando o universo nos oferece apenas um terreno baldio.

\section{Referências}

Bauman, Z. Modernidade e holocausto. Tradução de Marcus Penchel. Rio de Janeiro: Zahar, 1998.

Cruz, Afonso. A boneca de Kokoschka. 2 ed. Lisboa: Quetzal, 2012.

Gagnebin, J. M. Lembrar escrever esquecer. 2. ed. São Paulo: Editora 34, 2009.

Huston, Nancy. A espécie fabuladora: um breve estudo sobre a humanidade. Porto Alegre: L\&PM, 2010.

Seligmann-Silva, M. O local da diferença: ensaios sobre memória, arte, literatura e tradução. São Paulo: Editora 34, 2005.

Seligmann-Silva, M. (org). História, memória, literatura: o testemunho na era das catástrofes. São Paulo: Unicamp, 2003.

Recebido em 30 de novembro de 2019.

Aprovado em 2 de março de 2020.

\section{Resumo/Abstract/Resumen}

A boneca de Kokoschka e o direito a narrar-se de novo: o papel dos enredos de fé, amor e arte na reconstrução da identidade pós-trauma.

\section{Francilene Maria Ribeiro Alves Cechinel}

Norteado pelo ensaio A espécie fabuladora (2010), de Nancy Huston, o presente artigo propõe a discussão da obra $A$ boneca de Kokoschka (2010), do escritor português Afonso Cruz, a partir de seus enredos de fé, amor e arte, destacando o pa-

25 No livro escrito por Popa, o detetive Filip Marlov, contratado por Adele para encontrar o avô, remete ao detetive particular Philip Marlowe, personagem do famoso escritor de romances policiais noir Raymond Chandler. 
pel dessas narrativas no delicado processo de sobreviver e reconstruir-se após os traumas da experiência de guerra.

Palavras-chave: narrativas, trauma, Holocausto, Afonso Cruz.

A boneca de Kokoschka and the right to narrate yourself once more: faith, love and arts in post-trauma identity reconstruction

\section{Francilene Maria Ribeiro Alves Cechinel}

Guided by the essay A espécie fabuladora (2010), by Nancy Huston, this article proposes the analysis of $A$ boneca de Kokoschka (2010) by Portuguese writer Afonso Cruz, considering its intertwining of faith, love and arts, and highlighting the role of these narratives in the delicate process of surviving and reconstructing yourself after the traumas experienced in war.

Keywords: narratives, trauma, Holocaust, Afonso Cruz.

A boneca de Kokoschka y el derecho a narrarse de nuevo: fe, amor y arte en la reconstrucción de la identidad postrauma

\section{Francilene Maria Ribeiro Alves Cechinel}

A partir del ensayo A espécie fabuladora (2010), de Nancy Huston, este artículo propone un análisis de la obra $A$ boneca de Kokoschka (2010), del escritor portugués Afonso Cruz, a partir de sus fabulaciones en las que se mezclan fe, amor y arte; destacando el papel de estas narrativas en el delicado proceso de supervivencia y reconstrucción tras la traumática experiencia de la guerra.

Palabras clave: narrativas, trauma, Holocausto, Afonso Cruz. 